\title{
Transcriptome sequencing of a keystone aquatic herbivore yields insights on the temperature-dependent metabolism of essential lipids
}

\author{
Heidrun S. Windisch ${ }^{1,2^{*}}$ (D) and Patrick Fink $k^{3,4,5}$
}

\begin{abstract}
Background: Nutritional quality of phytoplankton is a major determinant of the trophic transfer efficiency at the plant-herbivore interface in freshwater food webs. In particular, the phytoplankton's content of the essential polyunsaturated omega-3 fatty acid eicosapentaenoic acid (EPA) has been repeatedly shown to limit secondary production in the major zooplankton herbivore genus Daphnia. Despite extensive research efforts on the biological model organism Daphnia, and the availability of several Daphnia genomes, little is known regarding the molecular mechanisms underlying the limitations in Daphnia related to dietary EPA availability.

Results: We used RNA-seq to analyse the transcriptomic response of Daphnia magna which were fed with two different diets - each with or without supplementation of EPA - at two different temperature levels (15 and $20^{\circ} \mathrm{C}$ ). The transcripts were mapped to the D. magna genome assembly version 2.4 , containing 26,646 translations. When D. magna fed on green alga, changing the temperature provoked a differential expression of 2001 transcripts, and in cyanobacteria-fed daphnia, 3385 transcripts were affected. The supplementation of EPA affected 1635 (on the green algal diet), or 175 transcripts (on the cyanobacterial diet), respectively. Combined effects for diet and temperature were also observed (669 for the green algal and 128 transcripts for the cyanobacterial diet). Searching for orthologous genes (COG-analysis) yielded a functional overview of the altered transcriptomes. Crossmatched transcript sets from both feed types were compiled to illuminate core responses to the factors temperature and EPA-supplementation.

Conclusions: Our highly controlled eco-physiological experiments revealed an orchestrated response of genes involved in the transformation and signalling of essential fatty acids, including eicosanoid-signalling pathways with potential immune functions. We provide an overview of downstream-regulated genes, which contribute to enhance growth and reproductive output. We also identified numerous EPA-responsive candidate genes of yet unknown function, which constitute new targets for future studies on the molecular basis of EPA-dependent effects at the freshwater plant-herbivore interface.
\end{abstract}

Keywords: Omega-3 fatty acids, Eicosapentaenoic acid, Temperature, Gene expression, Daphnia

\footnotetext{
* Correspondence: heidrun.windisch@ime.fraunhofer.de

'Heinrich-Heine-University, Institute for Cell Biology and Zoology,

Universitätsstrasse 1, 40225 Düsseldorf, Germany

${ }^{2}$ Fraunhofer IME, Institute for Molecular Ecology, Am Aberg 1, 57392

Schmallenberg, Germany

Full list of author information is available at the end of the article
}

(c) The Author(s). 2019 Open Access This article is distributed under the terms of the Creative Commons Attribution 4.0 International License (http://creativecommons.org/licenses/by/4.0/), which permits unrestricted use, distribution, and reproduction in any medium, provided you give appropriate credit to the original author(s) and the source, provide a link to the Creative Commons license, and indicate if changes were made. The Creative Commons Public Domain Dedication waiver (http://creativecommons.org/publicdomain/zero/1.0/) applies to the data made available in this article, unless otherwise stated. 


\section{Background}

Primary producer biomass is typically of poor quality in herbivores, which limits the trophic transfer of energy through food webs to higher trophic levels (trophic transfer efficiency) [1]. In aquatic environments, the photosynthetic base of the food web consists of small unicellular phytoplankton that is consumed by herbivorous zooplankton. Several constraints on algal food quality have been demonstrated, as algae can be hard to either ingest or digest by herbivores [2, 3]. Further, they can provide an unbalanced supply (stoichiometry) of nutrients [4]. In many cases their biochemical composition does not meet the herbivores' demands in essential nutritional compounds, such as essential fatty acids $[5,6]$, sterols [7, 8], vitamins [9], or amino acids [10, 11].

In freshwater ecosystems, crustacean zooplankton of the genus Daphnia are the major pelagic herbivores, and form a crucial link between primary producers and consumers [12]. Beyond their key role in freshwater food webs, daphnids are a well-established model system of environmental toxicology, experimental ecology and evolution, due to their ecological importance and exceptionally high level of phenotypic plasticity [13-16]. The genomes of several Daphnia species have been sequenced, and it is therefore one of the few animal genera for which extensive ecological and genomic information is available $[17,18]$. Interestingly, all the complex and plastic responses of daphnids are generated from a relatively small genome $[17,19]$. This makes Daphnia an excellent animal model for gene expression studies in response to environmental cues, such as kairomone signalling of vertebrate and invertebrate predation, exposure to parasite spores, crowding, and grazing on toxic and non-toxic food sources [20-22].

Daphnids have been repeatedly shown to be highly affected by diets with an inappropriate supply of essential fatty acids, as they are unselective filter-feeders that cannot preferentially take up algal cells rich in particular lipids [23]. A lack or limiting availability of certain omega-3 ( $\omega 3$, and to a lesser degree $\omega 6)$ polyunsaturated fatty acids (PUFAs) has been shown to constrain somatic growth, reproduction, and population growth in several Daphnia species [24-26]. This is due to the fact that $\omega 3$ and $\omega 6$ PUFAs typically can only be synthesized by primary producers, and not by animals [5, 27-29]. These 'families' of PUFAs can therefore be considered as essential dietary constituents for most animals, including Daphnia [30].

Beyond their role in growth and reproduction, PUFAs are well recognised critical components of the so-called 'homeoviscous adaptation' of biological membranes to low temperatures [31]. This concept implies an incorporation of more highly-unsaturated fatty acids with 'bent' alkene chains (versus 'straight' chains of saturated alkanes in saturated fatty acids) to maintain high flexibility of cellular lipid bilayers at low temperatures with concomitant low molecular motion [32]. It has been shown that low temperatures increase Daphnia's demand for dietary PUFAs to allow the maintenance of normal physiology [33, 34] and behaviour [35]. Thus, food quality and temperature constitute intertwined factors that influence the expression of different phenotypes, in order to achieve the best possible performance through plastic acclimatory responses.

In particular, the availability of the highly unsaturated $\omega 3$-PUFA eicosapentaenoic acid (EPA, C-20:5 $\omega 3$ ) was repeatedly shown to be crucial for Daphnia growth and reproduction, via controlled PUFA supplementation experiments $[5,6,36]$. Aquaculture studies have shown reduced fitness and increased inflammatory responses in organisms from higher trophic levels - such as fish when $\omega 3$ fatty acids are limiting $[37,38]$, therefore it is of global importance to understand the molecular mechanisms triggered by EPA availability. Alarming prospects in connection with the future availability of EPA on a larger scale were proposed by the results of a metaanalysis, which connected higher water temperatures due to climate change - with reduced primary production of long chain PUFAs [39].

Despite the growing body of evidence underscoring the importance of dietary PUFAs in general - and of EPA in particular - our understanding of the molecular physiology underlying the PUFA/EPA metabolism, and the gene networks responsive to the availability of this critical dietary compound remain very limited. Heckmann et al. [40] conducted an in-silico analysis of the genome of Daphnia pulex, which produced the first insights on potential mechanisms that are affected by $\omega 6-$ eicosanoids. Proposed candidate genes are involved in signalling pathways deduced from the $\omega 6$-PUFA arachidonic acid (ARA, C-20:4 $\omega 6$ ), affecting prostaglandin and leukotriene signalling. These candidates were confirmed in follow-up gene expression studies [41-43]. However, it is important to emphasise that $\omega 6$ PUFAs (like ARA) are generally believed not to be interconvertible into $\omega 3$ PUFAs (such as EPA) in metazoans [30], although this has been questioned [44].

In this study, we hypothesise that dietary availability of EPA will affect specific gene networks connected to lipid metabolism, cellular signalling, and immune-regulating pathways; similar to that which has been demonstrated for eicosanoids derived from w6-PUFAs [40-42]. We aim to unravel the gene networks specific to dietary EPA availability using a single genotype (clone) of Daphnia magna as a model system. Since EPA is crucial for acclimation to low temperatures in D. magna [35], such gene networks may become particularly visible at lower temperatures. We thus employed a strictly controlled EPA 
supplementation experiment at two temperatures, in order to characterise gene expression patterns in $D$. magna using RNA-seq. We discuss these results in connection with the animals' respective growth performance and fatty acid composition. While an earlier study [6] focused exclusively on single target genes whose expression was dependent on dietary EPA availability, we here look for larger scale transcriptomic adjustments driven by different food types and EPA availability, which should yield insights on PUFA-dependent gene regulation networks. Due to the high level of control of the experimental factors, the results illuminate the genetic basis underlying EPA (and more generally $\omega 3$ PUFA)dependent metabolism in this keystone herbivore; these findings offer important insights for the wider field of herbivore ecology and physiology.

\section{Results}

\section{Physiological effects at whole animal level}

In our experiment, we fed D. magna with two different basal diets (GA - green alga, CY - cyanobacteria) that do not contain any long-chain (i.e. > C-18) polyunsaturated fatty acids to monitor physiological and transcriptomic effects of controlled supplementations with the essential C-20 $\omega 3$ PUFA EPA.
Somatic growth rates (SGR) - which are a good fitness proxy in cladocerans [45] — were strongly affected by EPA-availability (2way-ANOVA, $F_{5}, 48=411.318, p \leq$ 0.001 ) and temperature (2way-ANOVA, $F_{1}, 48=$ $2295.402, p \leq 0.001$; Fig. 1). Combined effects were also detected (2way-ANOVA, $F_{5,48}=28.779, p \leq 0.001$ ).

In general, growth rates were much lower at $15^{\circ} \mathrm{C}$, reaching only $56.8-61.7 \%$ of the performance at $20^{\circ} \mathrm{C}$. EPA had a positive effect on D. magna growth when fed with the green alga Acutodesmus obliquus at both experimental temperatures (GA + EPA $p \leq 0.001)$. Similarly, EPA improved the SGR when given as a supplement alongside the cyanobacterium Synechococcus elongatus $(\mathrm{CY}+\mathrm{EPA})$, at $20^{\circ} \mathrm{C}(p \leq 0.001)$ and $15^{\circ} \mathrm{C}(p=0.014)$.

Somatic growth rates were higher in all CY-treatments than in respective GA-fed cultures. As stated below (see Material and Methods), cyanobacterial diets were further supplemented with cholesterol and alpha linoleic acid in order to support the Daphnia to reach maturity (time point of sampling) on this poor diet, which may have enhanced growth rates to the observed levels.

At both temperatures, the supplementation with empty control liposomes $(\mathrm{GA}+\mathrm{C})$ had no effect on SGR $\left(20^{\circ} \mathrm{C} p=0.593 ; 15^{\circ} \mathrm{C} p \leq 0.881\right)$, indeed similar growth rates were observed when raising $D$. magna on supplement-free food or the respective supplementation

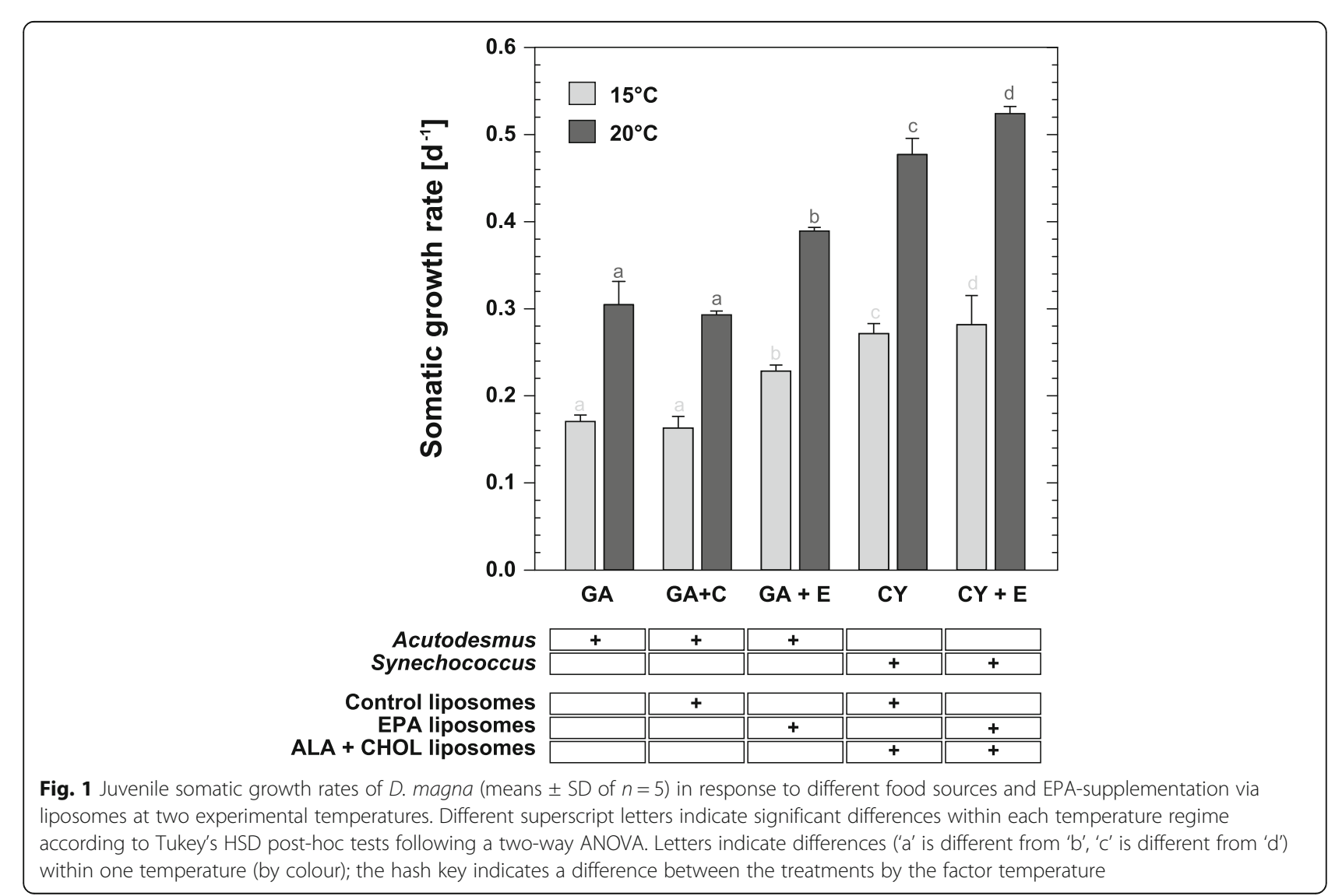


of control liposomes to the same basal diet. Although lower growth rates were determined at $15^{\circ} \mathrm{C}$, the animals were up to $26.8 \%$ heavier in absolute body mass (data not shown) than the individuals kept at $20^{\circ} \mathrm{C}$.

\section{EPA incorporation and fatty acid composition}

The supplementation of EPA and the natural differences in fatty acid composition in basal diets were considered as main drivers for the observed growth performances - and subsequently for the detected expression profiles - at the respective temperatures.

$D$. magna in EPA treatments accumulated supplemented EPA (Fig. 2a + b). Tissue EPA content of $D$. magna was significantly higher at $20^{\circ} \mathrm{C}$ compared to $15^{\circ} \mathrm{C}$.

The two different basal diets resulted in different tissue fatty acid compositions in D. magna (Fig. 3), with respect to the proportions of different fatty acid species (state of saturation). No significant differences were seen for saturated fatty acids (SAFAs), either from the basal diets or from the applied treatment conditions. However, monounsaturated fatty acid (MUFA) proportions differed significantly between diets. At $15{ }^{\circ} \mathrm{C}$, higher MUFA contents were found in CY-fed daphnids (for CY vs GA, $\mathrm{GA}+\mathrm{C}$ and $\mathrm{GA}+\mathrm{E} p<0.001$; for $\mathrm{CY}+\mathrm{E}$ vs $\mathrm{GA}, \mathrm{GA}+\mathrm{C}$ $p<0.001$; and $\mathrm{CY}$ vs $\mathrm{GA}+\mathrm{E} p=0.002)$. Similarly, higher contents were detected at $20^{\circ} \mathrm{C}$ (for $\mathrm{CY}$ as well as for $\mathrm{CY}+\mathrm{E}$ vs $\mathrm{GA}, \mathrm{GA}+\mathrm{C}$ and $\mathrm{GA}+\mathrm{E} p<0.001)$. A temperature effect of differing MUFA level was only detectable in the treatment $\mathrm{CY}+\mathrm{E}$ with $(p<0.001)$.
Polyunsaturated fatty acids (PUFAs) were found to be significantly higher in GA-food sources (all single GAs vs all single CYs $p<0.001$ ), with a tendency of higher recruitment at lower temperature, although this result was not significant.

\section{Differential gene expression overview}

Reads with "poor quality" were excluded (approved by FastQC analyses [46]). The total sequencing output of all samples was 1540.9 million reads, with an average read amount of 51.4 million reads $( \pm 4.1 \mathrm{SD})$ per sample (see Additional file 1: Table S1). We did not detect differences in the total expression output among treatments or temperatures, thus sequencing depth of the samples was comparable. With a mapping success of $79.89 \%$ ( \pm 0.69\% SD), we calculated FPKM values for further analyses for each replicate. To broadly compare expression profiles in terms of differential expression driven by food composition and culture temperature, we used the ArtNOG annotation to analyse the transcript diversity among different treatments (Fig. 4) by functional COG (categories of orthologous groups) assignments.

We distinguished differential responses by altered transcripts in D. magna fed either GA or CY. In general, the total amount of altered transcripts (driven by EPA, temperature and combined effects) was slightly different, with 3688 and 4305 altered transcripts for GA and CY, respectively. However, temperature-sensitive transcripts were much more pronounced when $D$. magna were raised on cyanobacteria (3385 temperature-specific sequences), whereas on the green algal diet far fewer

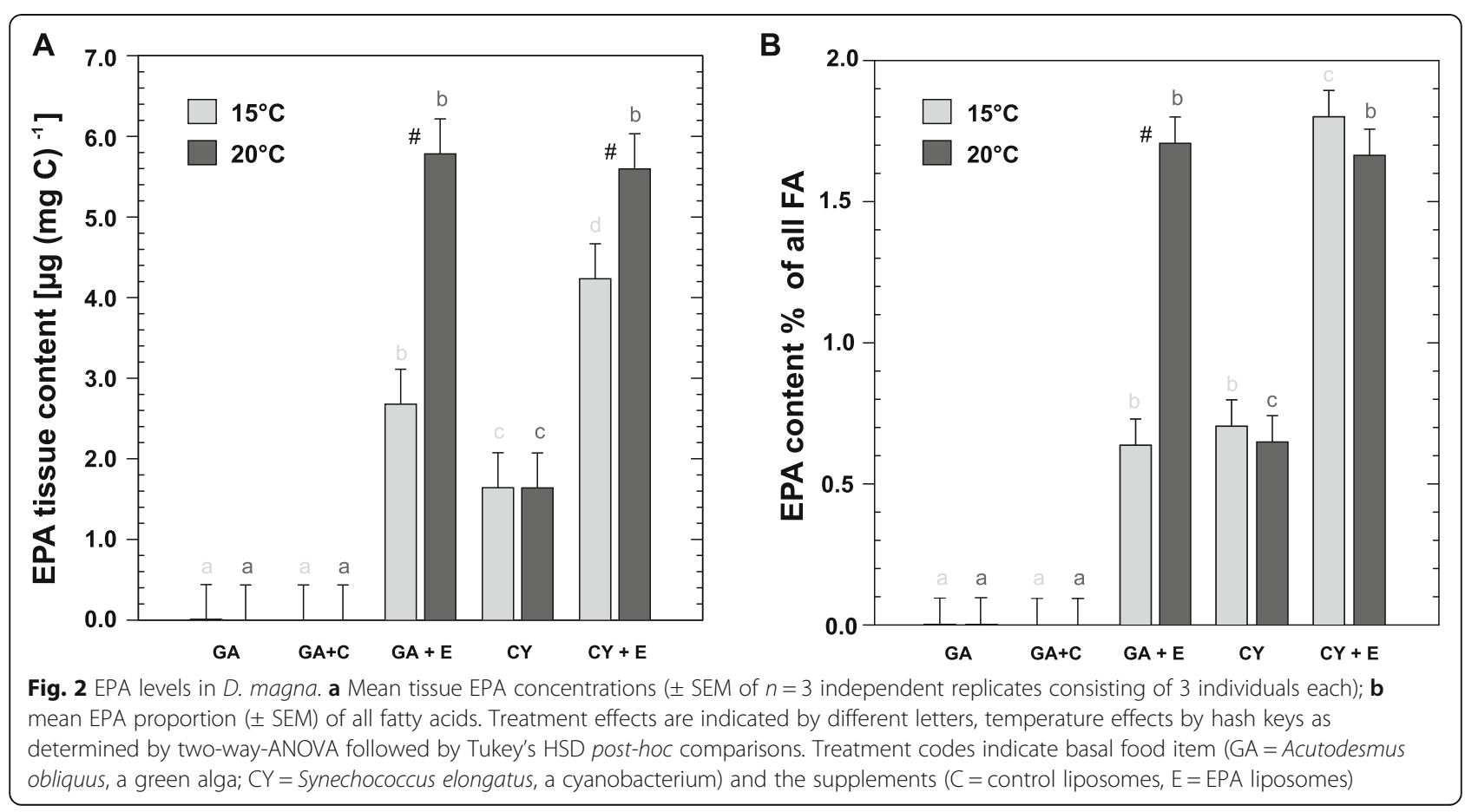




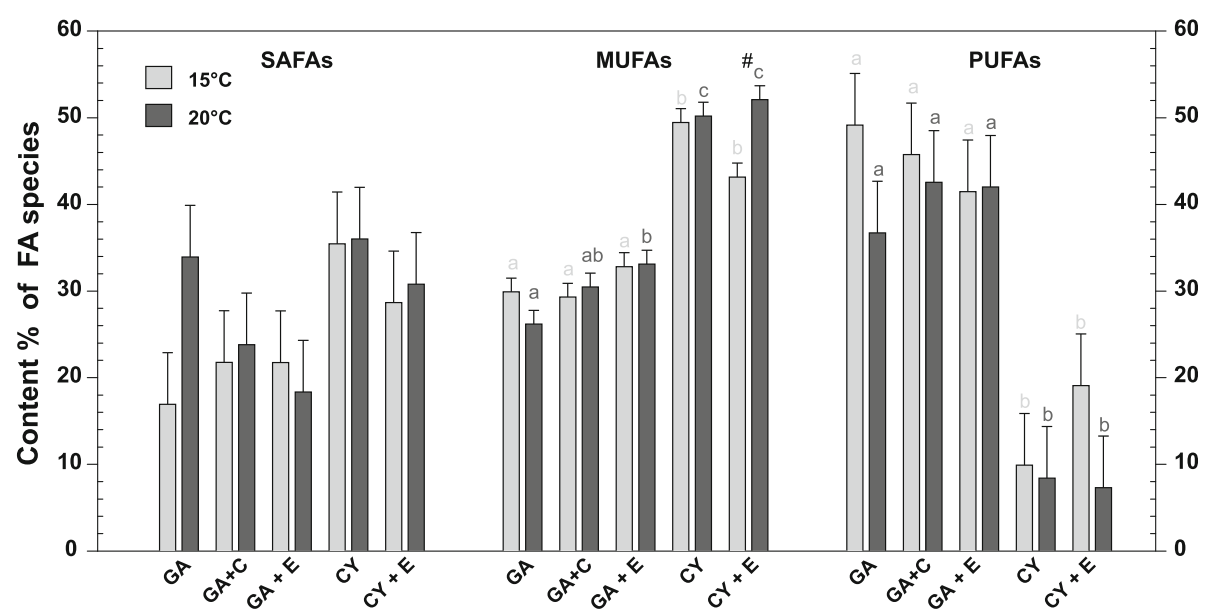

Fig. 3 Fatty acid composition of D. magna in the experiment. The three groups display the mean ( \pm SEM of $n=3$ ) proportion of saturated (SAFAs), monounsaturated (MUFAs) and polyunsaturated fatty acids (PUFAs) in D. magna in the respective treatments. Different letters indicate significantly different means within temperatures according to Tukey's HSD following two-way ANOVA, hash key indicates significant temperature effects. Treatment codes indicate basal food item ( $G A=$ Acutodesmus obliquus, a green alga; $C Y=$ Synechococcus elongatus, a cyanobacterium) and the supplements ( $C=$ control liposomes, $\mathrm{E}=\mathrm{EPA}$ liposomes)

\section{Expression patterns in COG categories}

\section{responsive transcripts} in respective category

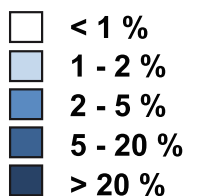

\section{Acutodesmus obliquus}

$350030002500200015001000500 \quad$ o

\begin{tabular}{|c|}
\hline 2,001 \\
1,635 \\
\hline 669
\end{tabular}

\section{Synechococcus elongatus}

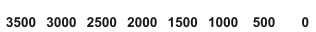

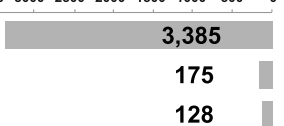

\section{temperature \\ EPA \\ combined}

Information storage

and processing

\section{temperature \\ EPA \\ combined}

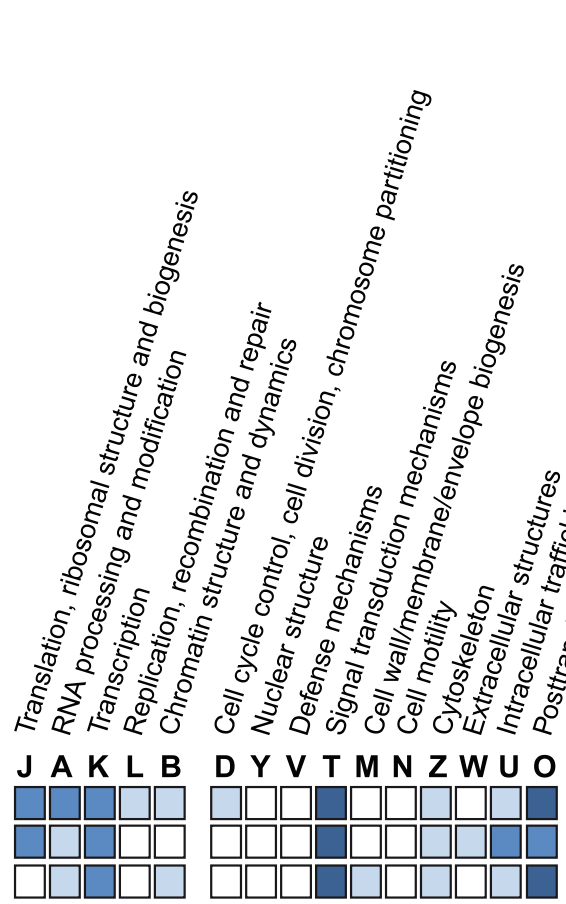

Cellular process and signaling

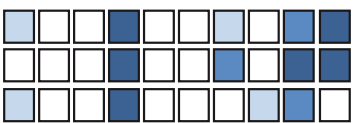

60

50

40

.$$
\text { (1) }
$$ 
transcripts (2001 sequences) were altered. The opposite trend was seen for transcripts that displayed EPA-sensitivity: GA treatments yielded 1635 alterations, whereas CY treatments showed only 175 differently expressed transcripts. Similarly, combined effects were more pronounced in GA diet (669 transcripts; CY: 128 transcripts). For both basal diets, altered expression levels were most prominently detected in categories (with known functions) $\mathrm{T}$ and $\mathrm{O}$, i.e. 'Signal transduction mechanisms' and 'Posttranslational modifications', in connection with the factors of temperature and EPA availability. Further changes in cellular processes and signalling categories were seen for 'Cytoskeleton' (Z) and 'Intracellular trafficking, secretion and vesicular transport' (U). Affected metabolic functions concerned 'Carbohydrate- '(G), 'Amino acid-' (E), 'Lipid-' (I) and 'Inorganic ion transport' (P), as well as 'Secondary metabolite biosynthesis, transport and catabolism' (Q). These alterations were paralleled by changes in the 'Transcription machinery' (K), as well as alterations in 'Translational-' ( $\mathrm{J}$ ) and 'RNA processing' (A) transcripts, which were strongly affected by the factor temperature.

The significant gene sets were plotted as volcano plots with a LOG-2-fold change of at least 1 against the adjusted $p$-values to give a general overview on the strongest responses (see Additional file 5 and respective data in Additional file 6).

\section{Core response profiles of affected transcripts}

To provide a more detailed overview of the large set of responsive genes depicted in Fig. 4, we further analysed genes in the respective categories to extract common responses in connection with the factors: temperature, EPA availability, and combined effects of both factors. From the most prominent categories, we cross-matched congruently regulated transcripts in GA and CY treatments to obtain basal diet-independent gene expression patterns (Table 1 and Additional file 2, Additional file 3, Additional file 4).

In total, we found 381 transcripts with a specific functional artNOG assignment that were affected by temperature (details in Additional file 2). The strongest altered gene expression was detected in the cluster of 'Information storage and processing', indicating a transcriptomic remodeling driven by temperature. Most of the genes were up-regulated at $15^{\circ} \mathrm{C}$ when compared to $20^{\circ} \mathrm{C}$. This may not only be provoked by the necessity of different functions, but also by compensation to maintain efficient reaction norms through increased transcript amounts at lower temperatures. To a lesser extent, this holds also for the COG clusters 'Cellular processes and signalling', as well as for genes in 'Metabolism' with more complex patterns. Here, functional changes became visible that were not thoroughly connected to compensation strategies. The overall increments in gene expression profiles also varied with the applied basal diet, often with higher expression levels in GA diets than in CY. Interestingly, most temperatureresponsive genes of all clusters display a generally higher expression level when EPA was available (see Additional file 2). Specific expression profiles will be detailed and discussed below with respect to the functional patterns.

Table 1 Overview of altered transcripts in COG regulated independent from basal diets. Two-way ANOVA results of D. magna expression profiles were cross-matched [47] between GA and CY diets to determine common gene expression patterns in functional COG groups. Resulting transcript numbers are given in connection with the respective factors

\begin{tabular}{|c|c|c|c|c|c|}
\hline COG cluster & COG & Category description & Temperature & EPA & Interactions \\
\hline \multirow[t]{3}{*}{ Information storage and processing } & J & Translation, ribosomal structure and biogenesis & 31 & 2 & 0 \\
\hline & A & RNA processing and modification & 54 & 0 & 0 \\
\hline & K & Transcription & 27 & 0 & 0 \\
\hline \multirow[t]{4}{*}{ Cellular processes and signalling } & $\mathrm{T}$ & Signal transduction mechanisms & 50 & 2 & 1 \\
\hline & Z & Cytoskeleton & 48 & 1 & 0 \\
\hline & U & Intracellular trafficking, secretion, and vesicular transport & 9 & 1 & 0 \\
\hline & $\mathrm{O}$ & Posttranslational modification, protein turnover, chaperones & 44 & 1 & 0 \\
\hline \multirow[t]{5}{*}{ Metabolism } & G & Carbohydrate transport and metabolism & 17 & 0 & 0 \\
\hline & $\mathrm{E}$ & Amino acid transport and metabolism & 39 & 1 & 1 \\
\hline & । & Lipid transport and metabolism & 22 & 0 & 0 \\
\hline & $\mathrm{P}$ & Inorganic ion transport and metabolism & 20 & 1 & 0 \\
\hline & Q & Secondary metabolites biosynthesis, transport and catabolism & 20 & 0 & 1 \\
\hline \multirow[t]{3}{*}{ Poorly characterised } & $\mathrm{R}$ & General function prediction only & 100 & 2 & 1 \\
\hline & S & Function unknown & 97 & 2 & 0 \\
\hline & $x$ & No match in artNOG & 104 & 2 & 1 \\
\hline Total & & & 682 & 15 & 5 \\
\hline
\end{tabular}


Far fewer genes were detected for a common response to EPA (15 candidates) or in connection with combined effects (5 candidates; see Table 1 and Additional file 3 ). The selection of shared altered transcripts between basal diets did include candidates with very different levels of transcript amount.

Many EPA-influenced genes displayed a downregulation with supplementation, in particular on the GA diets. An exception to this are the transcripts of the carboxylic ester hydrolase and the aromatic-L-aminoacid decarboxylase, which were expressed at the highest levels in animals on GA diets supplemented with EPA. The first may be attributed to lipid metabolism although jet assigned with artNOG category " $\mathrm{R}$ - functional prediction only" - the second is part of amino acid metabolism, and is involved in cell communication and signalling, as this enzyme catalyses the production of dopamine, serotonin, tryptamine, and histamine.

In animals fed CY-EPA diets, the highest expression levels were observed for endo-beta-1.4-mannanase, animal haem peroxidase, and THAP domain-containing protein, which are involved in fructose-mannose metabolism, cyclooxygenase activity, and the regulation of transcription, respectively. Here, a contrasting regulation of transcripts between the different basal diets and EPA supply becomes very explicit.

Genes regulated congruently in both basal diets were Myosin-IB, an uncharacterised protein (KZS03735.1), Angiopoetin-1 receptor-like protein, and Glycerol ether metabolic process (protein); with a down-regulation while EPA is available.

Our statistical analysis, followed by a cross-match of significant genes between diets, yielded six genes that display combined effects of temperature and EPA availability (see Additional file 3). The highest expression level was detected for Cytochrome P450. At the higher temperature, this enzyme was upregulated in the $\mathrm{CY}+$ EPA diet, and at the lower temperature in the GA + EPA regime. Transcripts of (putative) Trypsin-7, Endo-beta1.4-mannanase, as well as Opsin Rh6, were similarly regulated, with higher levels at lower temperature in $\mathrm{CY}+$ EPA diets, and were repressed at the higher temperature in GA + EPA diets.

\section{Discussion}

We studied transcriptomic effects of dietary EPA availability in combination with temperature to disentangle responsive gene networks underpinning the beneficial effects of this long chain $\omega 3$-PUFA on a physiological level. We further explore these effects by quantifying somatic growth rates as a fitness proxy, together with the animals' fatty acid composition. This allows us to discriminate gene expression patterns indicative of a complex interplay between resource availability and temperature responses in the aquatic model herbivore Daphnia magna.

\section{Physiological performance and fatty acid composition}

As for most animals, the fatty acid composition of Daphnia sp. reflects the composition of their diet [48]. In nature, the occurrence of PUFA-rich phytoplankton in lakes at cooler temperatures in spring matches the nutritional demand of zooplankton at the beginning of this season, providing high proportions of PUFAs for growth and reproduction [49], as well as for membrane remodelling [32]. Seasonal shifts in temperature and food availability should therefore be mirrored in altered transcript expression with signatures that are particularly attributable to these factors.

In our analysis, responses in life history traits in connection with EPA availability at different temperatures - demonstrated by impaired growth when EPA was limiting (Fig. 1) - showed that Daphnia cultivated at $15^{\circ} \mathrm{C}$ displayed a higher demand for EPA than specimens at $20^{\circ} \mathrm{C}$, which is in line with the findings of an earlier study [50]. However, EPA levels of D. magna were higher at $20^{\circ} \mathrm{C}$ (Fig. 2), contrary to the assumption that more EPA should be required at $15^{\circ} \mathrm{C}$ for homeoviscous adaptation. Similar results have been found previously for the same temperature regime $[50,51]$.

The total amount of EPA as a proportion of total body mass in $D$. magna is higher at the lower temperature. Nevertheless $D$. magna may have been ultimately limited by EPA availability due to the enhanced PUFA demand at lower temperatures. A higher amount of EPA accumulation in somatic tissue at $20^{\circ} \mathrm{C}$ than at $15^{\circ} \mathrm{C}$ is further supported by a recent study [51].

Overall, when we analysed the daphnids' fatty acid (FA) composition with respect to saturation state (SAFAs, MUFAs and PUFAs; see Fig. 3) almost no temperature-effects were visible within the different food types (except for MUFAs in the CY + EPA treatment). Consequently, it is likely that the applied thermal difference of $5^{\circ} \mathrm{C}$ was not severe enough to alter the animals' FA contents.

\section{Gene expression}

By assessing gene expression profiles in D. magna under strictly controlled experimental conditions, we were able to attribute particular functional changes specific to temperature and EPA availability. In general, temperature elicits large responses connected to RNA and DNA related processes ("Information storage and processing”, see Fig. 4), which are represented by a complex network of genes involved with replication as well as with transcription and translation. This key abiotic factor also provoked the alteration of transcripts that affect signal transduction mechanisms, posttranslational 
modification, as well as carbohydrate-, amino acid- and lipid transport mechanisms, and inorganic ionic transport processes.

Although the effect size of EPA altered transcripts was lower than the temperature-induced effects, this dietary constituent is nevertheless a major driver of improved growth at the physiological level.

The transcriptomic responses so far analysed in connection with long chain polyunsaturated fatty acids rely on studies of enzymes that are involved in eicosanoid synthesis of the "arachidonic pathway" [52]. These enzymes are known to convert eicosanoids into important signalling molecules, such as prostaglandins or leukotrienes in invertebrates, but also in mammals $[40,53]$. In our study, EPA availability provoked various functional changes in translation and transcription, but also in signal transduction mechanisms, changes in intracellular trafficking, as well as altered transcript levels for carbohydrate-, amino acid-, and lipid metabolism that are detailed below.

\section{Information storage and processing}

In this cluster, the strongest thermal effects are seen for the categories 'RNA processing and modification' (category A); 'translation, ribosomal structure and biogenesis' (J), and 'transcription' (K). Adjustments in the transcriptome become visible here, as these functions are modulated as a first response to the altered conditions. A high proportion of maintenance costs is attributed to regulation of this gene, which compensates effects of bio-physical reaction norms [54-56]. Generally, higher expression values were observed at the colder temperature, and were more enhanced than in other functional classes, such as 'cellular processes and signalling' or 'metabolism' (see Additional file 2). This effect is known as the compensatory effect, and was previously shown to vary between clones of $D$. pulex due to local adaptation [57]. Many candidates attributed in this cluster through artNOG annotation showed high transcript levels at both lower temperature and dietary EPA availability. This indicates adjustments of the transcriptome in response to changes in both factors.

\section{Signalling}

Numerous G-protein signalling transcripts, as well as serine/threonine kinases and opsins, were found to be thermally sensitive and were elevated with dietary EPA availability. Such candidates are potential mediators of anti-inflammatory processes, and are connected to healing and growth of cells in mammals [58]. Further, RAs and Ran- transcripts (RAs-related nuclear protein) that are factors involved in G-protein signalling affecting gene expression cascades involved in cell growth, differentiation and survival [59] - were upregulated. It is likely that RAs and Ran transcripts mediate sensing and signalling cascades for growth in Daphnia and other invertebrates. Similarly, the production of resolvins and protectins, molecules derived from EPA as well as from the longer docosahexaenoic acid (DHA, 22:6 $\omega 3$ ), are involved in cytokine and leukotriene signalling via Gproteins [60]. Transcripts of signalling cascades involving stimulators like dopamine or serotonin (products of the aromatic-L-amino-acid decarboxylase) were found to be upregulated in the EPA treatments. It remains to be investigated whether such products do function as neurotransmitters, or if they serve other endocrine functions in invertebrates. The first indication for the utilization of dopamine in Daphnia sp. was found in connection with predatory stress [61].

We also identified transcripts of cytochrome P450 in connection with the combined effects of temperature and EPA availability (Additional file 3). This is an important indicator for the biotransformation of EPA. Potential mechanisms are the conversions of EPA into five regioisomeric epoxyeicosatetraenoic acids (EETeTrs) and $\omega /(\omega-1)$ - hydroxyeicosapentaenoic acids (19- and 20-HEPE) [62], which mediate (at least in mammals) a delicate balance between pro- and anti-inflammatory responses [63].

Numerous gene families of cytochrome P450, as well as pseudogenes, have been identified across the animal kingdom [64]. For Daphnia, 75 functional CYP genes and 3 pseudogenes belonging to 4 clans, 13 families, and 19 subfamilies are so far identified [65]. However, the particular functional implications for many of these genes are still to be determined.

\section{Cellular structure and metabolism}

The higher growth rates were paralleled by higher expression of genes for cytoskeletal structures, accompanied by induced growth factor receptors and fibronectin, which were expressed at higher levels at $15^{\circ} \mathrm{C}$ when EPA was available.

The different profiles of carbohydrate metabolic transcripts ( $G$, but also in E) maltase, amylase and alphaglucan branching enzymes indicate a different quality of the basal food sources, as well as different energetic demands at both temperatures. Whilst sugars seem to be strongly metabolized at $20^{\circ} \mathrm{C}$, glycogen anabolism becomes more effective at $15^{\circ} \mathrm{C}$. This may be due to the fact that a faster metabolism is connected to a higher temperature, and is thus accompanied by a higher demand for sugars; this is mirrored by higher growth rates at the physiological level. Carbohydrate metabolism was also differentially regulated when Daphnia $s p$. were challenged with diets of different qualities in terms of nutrient stoichiometry [66], which may indicate that this is a very general response to food quality alterations. Genes 
in carbohydrate metabolism involved in inflammatory processes (SAPA), or connected to chitin and moulting (chitotriosidase), were also regulated in a temperaturedependent manner; these do however reflect a higher variation that may mirror the variability of individuals in sample pools.

Despite low transcriptional levels in the GA-diet regime, peptidases like trypsin or chymotrypsin, aminotransferases and metallopepdiases were up-regulated in CY diets, especially at the lower temperature (E). This was also mirrored in the expression of Eip55E (Ecdysteroid-inducible polypeptide 55 subunit E), which is involved in sulphur amino acid metabolic processes like cysteine and glutathione biosynthesis.

The different expression profiles in carbohydrate and amino acid metabolism indicate a recruitment of different enzymes to extract energetic compounds like sugars or amino acids from the different basal diets [67]. Different digestive efforts for CY-diets are indicated through high expression levels of metallopepdidases, trypsins, and aminotransferases, as well as by chaperones like Tcomplex proteins. Therefore, different basal diets provoke different phenotypes to handle and digest the different food items.

In the 'lipid metabolism' category (I), high levels of acyl-CoA dehydrogenases were expressed at $20^{\circ} \mathrm{C}$, especially when EPA was available. This indicates the transcription of RNAs related to the degradation of fatty acids. Transcript levels for transporters and intracellular transport structures associated with the transport mechanisms of long chain fatty acids were up-regulated when EPA was absent. This may be a mechanism to cover the higher demand for long chain PUFAs under EPA limitation. The higher expression levels of fatty acid transporters was accompanied by the expression of a transporter in the category 'inorganic ion transport and metabolism' (P), as well as by $\mathrm{ABC}$ transport proteins (ATP-Binding Cassette sub-family $\mathrm{C} /$ member 4 ) and cytochrome P450 305a1, which are involved prostaglandinmediated signalling $(\mathrm{Q}$, secondary metabolites).

High vitellogenin levels were pronounced in GA + EPA diets, accompanied by the expression of glycerol-3phosphate acyltransferase and acyl-CoA-binding domaincontaining protein 7 , with slightly higher (perhaps compensatory) levels at $15^{\circ} \mathrm{C}$, this may be involved in the biogenesis of vitellogenin, as previously observed [43]. Further, a secretory phospholipase A2 was induced, indicating increased effort to digest liposomal-supplemented diets.

High levels of dynein, myosin, and tubulin $(\mathrm{Z})$ indicate a remodelling of the cytoskeleton at lower temperatures. As the solubility and viscosity of the cytosol seems to be affected, a structural remodelling is indicated by the latter transcripts that are further supported by EPA availability. In this context, higher levels of fibronectin and endothelial growth factor receptor indicate a mediation of processes involved in cell division and growth [68].

Expressed candidate genes connected to 'inorganic ion transport and metabolism' (P) were up-regulated in animals feeding on cyanobacteria at $20^{\circ} \mathrm{C}$. Further gene upregulation occurred at $15^{\circ} \mathrm{C}$, which indicates dynamic adjustments of the osmotic balance at the lower temperature. $\mathrm{Ca}^{2+}$ - and serotonin transporters were particularly more strongly expressed at the lower temperature in the GA- diet supplemented with EPA. This matches the observed pattern for G-protein transcripts and conjoined candidates in category $\mathrm{T}$, which may contribute to the same messaging pathway [69]. Similarly, cytochrome P450 305a1 transcript displayed the same pattern in the category $\mathrm{Q}$ 'secondary metabolites...', which may also indicate a conjoined function in a signalling pathway. Interestingly, other Cytochrome P450-like proteins seem to be highly temperature sensitive, and were expressed with low or high levels in GA + EPA diets at $20^{\circ} \mathrm{C}$ and $15^{\circ} \mathrm{C}$, respectively.

Cytochrome $\mathrm{P} 450$ transcripts and subsequent proteins seem to play an important role in the metabolism and potential transformation of EPA into signalling cascades. Potential pathways for a transformation of the long chain polyunsaturated fatty acid EPA into other endocrine signalling molecules were proposed by $[40,53]$, these are: the cyclooxygenase (COx) pathway; 2) the lipoxygenase (LOX) pathway; or 3) the cytochrome P450 pathway. Recent expression studies, however, have shown that COx expression is not affected by EPAavailability $[43,52]$, and so far, no LOX genes have been found in Daphnia species [43]. Overall, our study delivers a profound insight into EPA-connected metabolism, and indicates that a transformation into endocrine signalling may rely on Cytochrome P450-based conversions; these outcomes should be explored in detail by further studies.

\section{Conclusions}

This study illuminates the plastic transcriptional responses in Daphnia magna to different food types and temperature regimes. The expression patterns in different phenotypes were highly dependent on the dietary availability of the $\omega 3$-polyunsaturated fatty acid EPA. Our results suggest a distinct cascade effect, utilizing different forms of cytochrome P450 to mediate sensing the essential EPA compound by transformation and subsequent G-protein signalling. Affected target genes then stimulate further transcription, upregulate transport mechanisms of intermediates, and stimulate cellular growth and reproduction. Altogether, this promotes a positive overall physiological performance. This is the first time that the orchestrating gene responses of Daphnia to these stimuli are explicitly demonstrated. Our 
study thus reveals some of the molecular mechanisms underlying the positive effects of a particular dietary omega-3 fatty acid, and constitutes an important resource of transcriptional patterns, even in genes with little or no annotation. Further, we propose that many new candidates for future investigations on the characterisation of EPA-related pathways are to be found in the currently uncharacterised genes (see expression profiles: Additional file 4), which can be now be annotated to be EPA-responsive.

Since cladoceran zooplankton forms the link in the trophic transfer of matter and energy between primary producers to higher levels in the food chain, this is an important step for our understanding of resource-driven limitation at the aquatic plant-herbivore interface.

\section{Methods}

\section{Food cultures}

The green alga (GA) Acutodesmus obliquus and the cyanobacterium (CY) Synechococcus elongatus served as food sources. The diets were chosen to monitor effects of the fatty acid EPA via supplementation, as they do naturally not contain long chain (> 18 C) $\omega 3$ PUFAs [50, 70, 71].

Respective culture conditions of all used food sources are listed in Table 2.

\section{Animals and experimental design}

Daphnia magna originating from the pond Driehoek in Heusden (clone P132.85; The Netherlands; N5144'01", $\left.E 5^{\circ} 08^{\prime} 17^{\prime \prime}\right)$ were used for the experiments. Aerated tap water was aged for at least 2 days and was used as culture medium after sterile-filtration $(45 \mu \mathrm{m})$. The animals were kept under dim light conditions and were precultured at either $15^{\circ} \mathrm{C}$, or $20^{\circ} \mathrm{C}$ for at least 2 months. A maximum density of 15 individuals $\mathrm{L}^{-1}$ was not exceeded. Feeding was based on green algal diet (A. obliquus) with a standardized amount of $2 \mathrm{mg}$ carbon $\mathrm{L}^{-1}$ every second day during pre-culture.

Juveniles for experiments originated from the third clutch (parthenogenetic offspring) and were collected within $8 \mathrm{~h}$ after release from the mothers' brood pouch. After pooling, neonates were randomly distributed into vessels containing $600 \mathrm{ml}$ tap water with experimental diet and were either incubated at $20^{\circ} \mathrm{C}$ or $15^{\circ} \mathrm{C}$. The exposure medium with food and supplements was exchanged on a daily basis $\left(20^{\circ} \mathrm{C}\right)$ or every other day $\left(15^{\circ} \mathrm{C}\right)$.

Food treatments comprised a green algal (GA), or cyanobacterial $(\mathrm{CY})$ basal diets, as well as supplemented treatments with EPA liposomes (GA + EPA, CY + EPA). To control that liposomes themselves had no effect we included a control $(\mathrm{GA}+\mathrm{C})$ supplementing the empty vector. All conditions were replicated with $n=5$. Each replicate comprised 15 individuals.

Liposomes were prepared as according to MartinCreuzburg et al., 2008 [74]. Individuals were sampled when they reached maturity, indicated by the deposition of the first clutch of eggs into their brood pouch. As $D$. magna requires a minimum of PUFASs and sterols to produce offspring [8], cyanobacterial diets were further supplemented with at alpha linoleic acid (ALA, C-18:3 $\omega 3)$ and cholesterol to ensure the reach of the sampling end-points. The total supplementation loading for all treatments was standardized to a concentration of $320 \mu \mathrm{l}$ liposomes $\mathrm{L}^{-1}$.

Sampling was carried out by picking single individuals, rinsing them twice with deionized water, blotting them dry with lint-free tissue and shock-freezing them by use of liquid nitrogen. Samples were stored at $-80^{\circ} \mathrm{C}$ until extraction of RNA or fatty acids. Two individuals from each vessel were used for somatic growth rate analysis.

\section{Daphnia fitness parameters}

Somatic growth rates were monitored using the mean dry weight of two adult individuals from each replicate vessel when reaching maturity. As a reference we used the mean dry weight of 40 neonates at the beginning of the respective experimental temperature. All collected animals were rinsed with deionized water and then dried for $24 \mathrm{~h}$ at $60^{\circ} \mathrm{C}$. Drying and mass determination was done in (preweighed) aluminium boats. Somatic growth rates (SGR) were determined in accordance to Lampert et al. [45] to monitor whole animal fitness by the formula:

$$
S G R=\left[\left(\ln \left(m_{t}\right)-\ln \left(m_{0}\right)\right] / t\right.
$$

As Daphnia grows with an exponential rate, the natural logarithms were applied to final weights $m_{t}$ from each replicate and to the starting weight $m_{0}$ to calculate the net weight gain by their difference. Growth rates were than put into relation to the time period $t$, the

Table 2 Algal and cyanobacterial culture conditions and respective growth media

\begin{tabular}{|c|c|c|c|c|}
\hline Organism & Strain & Medium & Culture conditions & $\begin{array}{l}\text { Temperature and light } \\
\text { conditions }\end{array}$ \\
\hline Green alga Acutodesmus obliquus & SAG 276-3a & Z/4 [72] & $\begin{array}{l}5 \mathrm{~L} \text { semi-continuous batch culture with a } 20 \% \text { Vol. } \\
\text { replacement with fresh sterile medium every other day }\end{array}$ & $\begin{array}{l}20^{\circ} \mathrm{C} \text { and a constant } \\
\text { light intensity }\end{array}$ \\
\hline $\begin{array}{l}\text { Cyanobacterium Synechococcus } \\
\text { elongatus }\end{array}$ & SAG 89.79 & Cyano [73] & chemostat at a dilution rate of $20 \% \mathrm{~d}^{-1}$ & of $\sim 60 \mu \mathrm{mol}$ photons $\mathrm{m}^{-2} \mathrm{~s}^{-1}$ \\
\hline
\end{tabular}


number of days until reaching maturity, which was indicated by formation of the first clutch of offspring in their brood chamber [75].

\section{Fatty acid composition}

The analysis of fatty acid composition was done by means of fatty acid methyl esters (FAME), which were subsequently quantified by gas chromatography (GC). For each treatment 3 mature $D$. magna from each replicate (previously stored at -80 ) were extracted with $5 \mathrm{ml}$ extraction reagent (ExR, dichloromethane/methanol (2:1, v:v)) over night at $4{ }^{\circ} \mathrm{C}$. Internal standards with uneven length of the fatty acid chain, which do not naturally occur in Daphnia or Alga, were added to the extraction as a mass reference: $10 \mu \mathrm{g}$ heptadecanoic acid methyl ester $(\mathrm{C}-17: 0 \mathrm{ME})$ and $5 \mu \mathrm{g}$ tricosanoic acid methyl ester (C-23:0 ME). The extract was mixed on a vortexer and then sonicated for $1 \mathrm{~min}$. The extract was collected using a glass Pasteur pipet and another $3 \mathrm{ml}$ ExR were added to the tube containing the daphnids. After a second round of vortexing and sonication extracts were pooled and centrifuged at $5.000 \mathrm{rpm}$ for $5 \mathrm{~min}$ at room temperature to remove cellular debris. The solvent was evaporated under a constant stream of nitrogen until the sample was dried. By adding $5 \mathrm{ml}$ of $3 \mathrm{~N}$ methanolic $\mathrm{HCl}$ and incubation at $70^{\circ} \mathrm{C}$ for $20 \mathrm{~min}$ the sample was transesterified to built FAMEs. Extraction of FAMES was carried out by adding $\sim 2 \mathrm{ml}$ isohexane, vigorously vortexing for a minute and collection of the upper liquid phase. The remaining phase was again extracted with isohexane to minimize loss FAMES that were not transferred in the first round. After solvent evaporation, FAMEs were collected from the glass vial by pipetting $3 \times 100 \mu \mathrm{l}$, rinsing the walls of the vial. The extract was collected in a HPLC-vial. Again, the solvent was evaporated and FAMEs were finally dissolved in $50 \mu \mathrm{l}$ isohexane to concentrate and standardize samples for the GC measurement. For all measurements $1 \mu$ l FAME-extract was analyzed on a 6890-N GC System (Agilent Technologies, Waldbronn, Germany) equipped with a DB225 capillary column $(30 \mathrm{~m}, 0.25 \mathrm{~mm}$ i.d., $0.25 \mu \mathrm{m}$ film thickness, J\&W Scientific, Folsom, CA, USA). The instrument was run with the following settings: injector and FID temperatures were $200^{\circ} \mathrm{C}$; the initial oven temperature was $60^{\circ} \mathrm{C}$ for $60 \mathrm{~s}$, followed by a thermal ramp to $180{ }^{\circ} \mathrm{C}$ with $2{ }^{\circ} \mathrm{C} / \mathrm{s}$, then a ramp to $200^{\circ} \mathrm{C}$ with $0.83^{\circ} \mathrm{C} / \mathrm{min}$ followed by $630 \mathrm{~s}$ at $200^{\circ} \mathrm{C}$, followed by ramp to $220^{\circ} \mathrm{C}$ with $2{ }^{\circ} \mathrm{C} / \mathrm{s}$ followed by $630 \mathrm{~s}$ at $220^{\circ} \mathrm{C}$; helium with a flow rate of $0.025 \mathrm{ml} / \mathrm{s}$ was used as the carrier gas. The fatty acids were then quantified by referring to the mass and signals of internal standards and to standards for each FAME from mixtures of known composition $[5,76]$. Each calibration for single FA had a correlation coefficient $>0.98$. Single fatty acid contents were related to the carbon content of the body tissue using the previously determined carbon to dry mass conversion factor for body tissue, $0.41 \mu \mathrm{g}$ carbon ( $\mu \mathrm{g}$ dry mass $)^{-1}$ [77].

\section{Nucleic acid preparation and sequencing}

Based on their different fitness at the physiological level, which was monitored by means of somatic growth rates, we selected sample pools for RNA extraction. From both experimental temperatures we prepared RNA from 4 treatment groups for sequencing with 3 replicates each. We did not include the GA (only food) treatment, as there were no differences to $\mathrm{GA}+\mathrm{C}$ on physiological level (SGR) or in PUFA composition. We pooled the material of 5 specimens for each replicate to ensure appropriate amounts for RNA extraction and comparability. We used the NucleoSpin RNA extraction kit (Machery und Nagel, Düren/Germany) according to the manufacturer's instructions for total RNA extraction. To ensure, that traces of genomic DNA do not give false signals, we additionally used the Turbo DNA-free Kit (Invitrogen, Karlsruhe/Germany) as an additional cleanup. The RNA-extract was analyzed on a Bioanalyzer (Agilent Technologies, Santa Clara/USA) to determine quality and quantity of the RNA. Samples with $\mathrm{OD}_{280} /$ $\mathrm{OD}_{260} \geq 2.0, \mathrm{OD}_{280} / \mathrm{OD}_{230} \geq 2.0$ and $\mathrm{RIN} \geq 8.0$ were used for sequencing. The following cDNA library construction, fragmentation as well as sequencing was conducted at the University of Cologne's 'Cologne Centre for Genomics' (CCG). cDNA libraries were built for each sample and subsequently sequenced on an Illumina HiSeq 4000 platform in the paired-end $75 \mathrm{bp}$-mode. All 30 samples were run in pools ( 5 treatment groups with 3 replicates at two temperatures) distributed to two lanes. The first raw data cleaning (clipping and trimming) was done by the CCG as well using Trimmomatic [78].

\section{Data analysis and processing}

We sequenced mRNA of pools of $5 \mathrm{D}$. magna individuals from 4 different food treatments $(\mathrm{GA}+\mathrm{C}, \mathrm{GA}+$ $\mathrm{EPA}, \mathrm{CY}, \mathrm{CY}+\mathrm{EPA}$ ) originating from either $15^{\circ} \mathrm{C}$, or $20^{\circ} \mathrm{C}$ with 3 replicates each. We used FastQC [46] to monitor sequence quality at a critical threshold score $>$ 30, which was passed for samples. Reads originating from single treatment replicates were mapped to $D$. magna genome (NCBI BioProject accession No. PRJNA298946, comprised of $\sim 130$ million bases) to gather single specific expression profiles. The reference database (v2.4) contains 26.646 translations (open access since April 2016). We used RSEM v.1.2.31 [79] connected to bowtie2 [80] for mapping and to generate FPKM values for transcript analysis.

To gather a more functional overview, we assigned the translations of genomic sequence data with orthologous groups using the eggNOG v. 4.0 database [81]. In 
particular, we assigned sequences with artNOGs (arthropod Non supervised Orthologous Groups, composed of 21 species in this group), which are grouped in COG (Categories of Orthologous Groups). For assignments we used BLASTp at an e-value cut-off $\leq 10^{-3}$ and a HSP cut-off length $\geq 33$ bases to provide additional information for categorization.

For differential gene expression analysis we used $\mathrm{MeV}$ software v. 4.8.1 [82] connected to edgeR [83]. Two-Way ANOVA was used on the basis of normalized FPKM values to identify differently expressed genes driven by EPAavailability and temperature at respective basal food sources.

In addition, $\mathrm{t}$-tests were conducted between treatments within temperatures, or vice versa characterise gene expression profiles at a critical threshold of $p \leq 0.01$. Responsive transcripts were analysed via cross-match (Hulsen, de Vlieg, \& Alkema, 2008) to gather consensus lists.

\section{Data validation}

To corroborate the RNA-seq data, we examinated the gene expression profiles of five selected candidate and housekeeping genes from our RNA-seq experiment in comparison to qPCR data from literature.

Selected transcripts were assessed in a former qPCRstudy by Schlotz et al. [42], who monitored the transcriptomic response of Daphnia magna fed with different natural food types. The experiments were carried out at $20^{\circ} \mathrm{C}$ and daphnids were fed with either a green alga (Scenedesmus obliquus, now Acutudesmus obliquus), or a cryptomonad (Cryptomonas spec.) until the generation of the third clutch of offspring. Cryptomonads naturally contain numerous omega-3-fatty acids, including EPA.

Schlotz et al. observed increased levels of vitellogenin [42] when the EPA-rich Cryptomonas spec. Was fed to D. magna. We made similar observations in a recent feed supplementation study [43], where D. magna fed with a green alga (Acutodesmus obliquus) showed lower levels of vitelloginin transcripts than EPA-supplemented daphnids. The same pattern was detectable in our RNAseq data. Vitellogenin transcripts (product accessions KZS21011.1, KZS21012.1 and KZS06496.1) were significantly increased (2-way ANOVA) when dietary EPA was available (in the set of "significant to food GA").

The transcript for juvenile hormone was another target in the study of Schlotz et al. [42]. They observed increased levels of juvenile hormone transcripts when $D$. magna were fed the EPA-rich food source Cryptomonas sp. The same pattern was detectable in our RNA-seq data (product accession KZS09289.1). Juvenile hormone was significantly increased (2-way ANOVA) when dietary EPA was available to D. magna.

Fatty acid binding protein 3 was another candidate gene derived from the study of Schlotz et al. [42]. They found a down-regulation when $D$. magna were fed the EPA-rich food source Cryptomonas sp. We detected the same pattern in our RNA-seq data when dietary EPA was available to D. magna (product accession KZS18357.1).

We further compared the expression of two housekeeping genes in our RNA-seq data (from the set "food GA non-significant") with qPCR expression data from earlier, published studies: Schwarzenberger et al. [84, 85] and Windisch and Fink [6] used glycerinaldehyde-3phosphate dehydrogenase (GAPDH) for normalisation of qPCR data. Respective transcript levels in our RNA-seq data (product accessions KZS15286.1, KZS06031.1, KZS02020.1, KZS01487.1, KZS01268.1, KZS98609.1, KZR98522.1) also displayed only minor variation among treatments, thus corroborating the house-keeping character of the target gene.

Similarly, Succinate Dehydrogenase (Suc-DH), used in the studies mentioned above $[84,85]$, did not appear to be under differential regulation under the different treatments of our study (product accessions KZS06688.1, KZS04241.1, KZR98715.1, KZS19960.1, KZS19824.1). Taken together, our RNA-seq data match published expression pattern from literature determined via qPCR. This hence corroborates that our expression profiles determined via RNA-seq are representative and comparable to other methodologies and studies.

\section{Supplementary information}

Supplementary information accompanies this paper at https://doi.org/10 1186/s12864-019-6268-y.

Additional file 1: Table S1. Summary of sequencing output and mapping success.

Additional file 2. Temperature significant gene expression profiles.

Additional file 3. EPA significant gene expression profiles and combined effects.

Additional file 4. Expression profiles of "poorly characterized" genes responsive to temperature, EPA and combined effects.

Additional file 5: Volcano plots of transcripts with LOG2-fold changes $>1$ (identified by two-way ANOVA, based on means of triplicates in each group). Respective values were plotted against the adjusted $p$-values. A respective COG-annotation of single transcripts was included by colour of the data points. Single data points were also labelled with product accession numbers for identification. The underlying data sets were exported as Additional file 6.

Additional file 6: Datasets of responsive gene sets with LOG2-fold change values, adjusted p-values and the respective COG category.

\section{Abbreviations}

+ C: Supplementation with control liposomes; + E or EPA: Supplementation with EPA liposomes; ALA: Alpha linoleic acid, C-18:3 w3; ANOVA: Analysis of variance; ARA: Arachidonic acid, C-20:4 w6; artNOG: Arthropod nonsupervised orthologous groups; BLAST: Basic Local Alignment Search Tool; bp: Base pair; C-17:0 ME: Standard for FAME analytics, heptadecanoic acid methyl ester; C-18: Fatty acids with total length of 18 carbon molecules; C20: Fatty acids with total length of 20 carbon molecules; C-23:0 ME: Standard for FAME analytics, tricosanoic acid methyl ester; CCG: Cologne Centre for Genomics; CDNA: Complementary DNA; COG: Categories of orthologous groups; COx: Cyclooxygenase; CY: Cyanobacterium (here in particular of the species Synechococcus elongatus); Cyano: Cyanophycea medium, used for the culture of Synechococcus elongatus); CYP: Cytochrome p-450; 
DHA: Docosahexaenoic acid, C-22:6 w3; DNA: Deoxyribonucleic acid; EETeTrs: Epoxyeicosatetraenoic acids; eggNOG: Database for orthologous groups hosed by the EMBL; EPA: Eicosapentaenoic acid, C-20:5 w3; ExR: Extraction reagent for lipids extraction; FA: Fatty acid; FAME: Fatty acid methyl esters; FastQC: Quality assessment software for sequencing data: FPKM: Fragments per kilobase of exon model per million reads mapped; GA: Green alga (here in particular of the species Acutodesmus obliquus); GCFID: Gas chromatography-flame ionization detector;

HEPE: Hydroxyeicosapentaenoic acids; HSP: High scoring pairs;

LOX: Lipoxygenase; MeV: Multi Experiment viewer; MUFA: Monounsaturated fatty acid; NCBI: National Centre for Biotechnology Information; PUFA: Polyunsaturated fatty acid; Ran: Ras-related Nuclear protein; Ras: Protein family involved in G-Protein signalling; RNA: Ribonucleic acid; RNA-seq: Ribonucleic acid sequencing; rpm: Rotations per minute; SAFA: Saturated fatty acid; SAG: International acronym for Culture Collection of Algae at Göttingen University, Germany; SAPA: Substrate-associated protein A; SD: Standard deviation; SEM: Standard error of means;

SGR: Somatic growth rate; THAP: Thanatos Associated Protein, indicates death-domain in protein; v:v: Percent of volumes; Z/4: Name of the medium used for Acutodesmus obliquus culture; $\omega 3$ : Fatty acid species with unsaturation (carbon double bond) at the $n-3$ position; $\omega 6$ : Fatty acid species with unsaturation (carbon double bond) at the n-6 position

\section{Acknowledgements}

We thank Eric von Elert from the University of Cologne for supporting this project with lab facilities and constructive discussions. We also thank Katja Preuß and Thomas von Einem for technical support. We are grateful for the open access provision of Daphnia magna genomic data by the "Daphnia Functional Genomics Resource" (Grant ID R24 GM078274, NIH National Institute of General Medical Sciences). We further acknowledge the computational support by Stephan Raub and Philipp Helo Rehs as well as the infrastructure provided by the "Centre for Information and Media Technology" (ZIM) at the University of Düsseldorf (Germany). We also thank Amy MacLeod for language editing of the manuscript.

\section{Authors' contributions}

PF and HW conceived and conceptualised the experiment. HW conducted the experiments and analysed physiological, fatty acid and transcriptomic data and wrote the first draft of the manuscript. Both authors read and approved the final manuscript.

\section{Funding}

The project was funded by the Institute of Zoology and Cell Biology of the Heinrich-Heine-University Düsseldorf and by project Fl1548/6-1 within the Priority Programme SPP 1704 "DynaTrait" funded by the Deutsche Forschungsgemeinschaft to PF. The funding bodies played no role in the design of the study and collection, analysis, and interpretation of data and in writing the manuscript.

\section{Availability of data and materials}

RNA-seq data are available at the NCBI sequence read archive under accession number SRP109969 with sample accessions SAMN07259933 SAMN07259947 $\left(20^{\circ} \mathrm{C}\right)$ and SRS2947545 - SRS2947559 $\left(15^{\circ} \mathrm{C}\right)$. A detailed description and overview of the respective sampling material is available under the BioProject accession number PRJNA391248. The results of the RNA-seq experiment are also accessible under the GEO entry GSE130674.

\section{Ethics approval and consent to participate}

The Daphnia magna clone P132.85 was isolated in 1994 by Luc de Meester (KU Leuven) and have been in culture under standardized conditions ever since. Specimen of the clone were kindly provided to the group "Aquatic chemical Ecology" headed by Prof. Eric von Elert in Cologne. No permissions for the experiments were necessary, as animal experiments on invertebrates (except cephalopods and higher crustaceans, which does not apply here) do not require regulatory approval according to $\S 8$ TierSchG of the national regulations of Germany.

\section{Consent for publication}

Not applicable.

\section{Competing interests}

The authors declare that they have no competing interests.

\author{
Author details \\ ${ }^{1}$ Heinrich-Heine-University, Institute for Cell Biology and Zoology, \\ Universitätsstrasse 1, 40225 Düsseldorf, Germany. ${ }^{2}$ Fraunhofer IME, Institute \\ for Molecular Ecology, Am Aberg 1, 57392 Schmallenberg, Germany. \\ ${ }^{3}$ Institute for Zoology, University of Cologne, Zülpicher Strasse 47b, 50674 \\ Köln, Germany. ${ }^{4}$ Department River Ecology, Helmholtz Centre for \\ Environmental Science, Brückstrasse 3a, 39114 Magdeburg, Germany. \\ ${ }^{5}$ Department Aquatic Ecosystem Analysis and Management, Helmholtz \\ Centre for Environmental Science, Brückstrasse 3a, 39114 Magdeburg, \\ Germany.
}

Received: 3 May 2019 Accepted: 6 November 2019

Published online: 21 November 2019

\section{References}

1. Elser JJ, Fagan WF, Denno RF, Dobberfuhl DR, Folarin A, Huberty A, Interlandi S, Kilham SS, McCauley E, Schulz KL, et al. Nutritional constraints in terrestrial and freshwater food webs. Nature. 2000;408(6812):578-80.

2. Porter KG. Selective grazing and differential digestion of algae by zooplankton. Nature. 1973;244:179-80.

3. Van Donk E, Hessen DO. Grazing resistance in nutrient-stressed phytoplankton. Oecologia. 1993;93:508-11.

4. Sterner RW, Elser JJ. Ecological stoichiometry: the biology of elements from molecules to the biosphere. Princeton: Princeton University Press; 2002.

5. von Elert E. Determination of limiting polyunsaturated fatty acids in Daphnia galeata using a new method to enrich food algae with single fatty acids. Limnol Oceanogr. 2002;47(6):1764-73.

6. Windisch HS, Fink P. The molecular basis of essential fatty acid limitation in Daphnia magna: a transcriptomic approach. Mol Ecol. 2018;27(4):871-85.

7. Martin-Creuzburg D, von Elert E. Ecological significance of sterols in aquatic food webs. In: Arts MT, Brett MT, Kainz MJ, editors. Lipids in Aquatic Ecosystems. New York: Springer; 2009. p. 43-64.

8. von Elert E, Martin-Creuzburg D, Le Coz JR. Absence of sterols constrains carbon transfer between cyanobacteria and a freshwater herbivore (Daphnia galeata). Proc R Soc Lond B Biol Sci. 2003;270(1520):1209-14.

9. Connelly SJ, Walling K, Wilbert SA, Catlin DM, Monaghan CE, Hlynchuk S, Meehl PG, Resch LN, Carrera JV, Bowles SM, et al. UV-stressed Daphnia pulex increase fitness through uptake of vitamin D3. PLoS One. 2015;10(7): e0131847.

10. Fink P, Pflitsch C, Marin K. Dietary Essential Amino Acids Affect the Reproduction of the Keystone Herbivore Daphnia pulex. PLoS One. 2011; 6(12):e28498.

11. Anderson TR, Boersma M, Raubenheimer D. Stoichiometry: linking elements to biochemicals. Ecology. 2004;85(5):1193-202.

12. Lampert W. Daphnia: development of model organism in ecology and evolution. In: Kinne O, editor. Book 21 Excellence in Ecology Series. International Ecology Institute: Oldendorf/Luhe, Germany; 2011.

13. Boersma M, Spaak P, de Meester L. Predator-mediated plasticity in morphology, life history, and behavior of Daphnia : the uncoupling of responses. Am Nat. 1998;152(2):237-48.

14. Tollrian R. Neckteeth formation in Daphnia pulex as an example of continuous phenotypic plasticity: morphological effects of Chaoborus kairomone concentration and their quantification. J Planct Res. 1993;15(11): 1309-18.

15. Hairston NG, Lampert W, Caceres $C E$, Holtmeier $C L$, Weider $L$, Gaedke U, Fischer JM, Fox JA, Post DM. Lake ecosystems: rapid evolution revealed by dormant eggs. Nature. 1999;401(6752):446.

16. Zhang L, Liu J, Liu H, Wan G, Zhang S. The occurrence and ecological risk assessment of phthalate esters (PAES) in urban aquatic environments of China. Ecotoxicology. 2015;24(5):967-84.

17. Colbourne JK, Pfrender ME, Gilbert D, Thomas WK, Tucker A, Oakley TH, Tokishita S, Aerts A, Arnold GJ, Basu MK, et al. The Ecoresponsive Genome of Daphnia pulex. Science (New York, NY). 2011;331(6017):555-61.

18. Colbourne JK, Singan VR, Gilbert DG. wFleaBase: the Daphnia genome database. BMC Bioinformatics. 2005;6(1):45.

19. Ye Z, Xu S, Spitze K, Asselman J, Jiang X, Ackerman MS, Lopez J, Harker B, Raborn RT, Thomas WK, et al. A New Reference Genome Assembly for the 
Microcrustacean Daphnia pulex. G3: Genes|Genomes|Genetics. 2017;7(5): 1405-16.

20. Huylmans AK, López Ezquerra A, Parsch J, Cordellier M. De novo transcriptome assembly and sex-biased gene expression in the cyclical parthenogenetic Daphnia galeata. Genome Biol Evol. 2016;8(10):3120-39.

21. Orsini L, Gilbert D, Podicheti R, Jansen M, Brown JB, Solari OS, Spanier KI, Colbourne JK, Rush D, Decaestecker E, et al. Daphnia magna transcriptome by RNA-Seq across 12 environmental stressors. Sci Data. 2016;3:160030.

22. Orsini L, Brown JB, Shams Solari O, Li D, He S, Podicheti R, Stoiber MH, Spanier Kl, Gilbert $\mathrm{D}$, Jansen $\mathrm{M}$, et al. Early transcriptional response pathways in Daphnia magna are coordinated in networks of crustacean-specific genes. Mol Ecol. 2017;00:1-12.

23. Demott WR, Müller-Navarra D. The importance of highly unsaturated fatty acids in zooplankton nutrition: evidence from experiments with Daphnia, a cyanobacterium and lipid emulsions. Freshw Biol. 1997;38(3):649-64.

24. Becker C, Boersma M. Differential effects of phosphorus and fatty acids on Daphnia magna growth and reproduction. Limnol Oceanogr. 2005;50(1): 388-97.

25. Ravet JL, Brett MT, Müller-Navarra DC. A test of the role of polyunsaturated fatty acids in phytoplankton food quality for Daphnia using liposome supplementation. Limnol Oceanogr. 2003;48(5):1938-47.

26. Sperfeld E, Wacker A. Temperature- and cholesterol-induced changes in eicosapentaenoic acid limitation of Daphnia magna determined by a promising method to estimate growth saturation thresholds. Limnol Oceanogr. 2011;56(4):1273-84.

27. Burr $\mathrm{GO}$, Burr MM. A new deficiency disease produced by the rigid exclusion of fat from the diet. J Biol Chem. 1929;82:345-67.

28. Cook HW, McMaster CR. Chapter 7 Fatty acid desaturation and chain elongation in eukaryotes. In: Vance DE, Vance JE, editors. New Comprehensive Biochemistry, vol. 36. Paris: Elsevier; 2002. p. 181-204.

29. Mukhopadhyay R, Smith W. Essential fatty acids: the work of George and Mildred Burr. J Biol Chem. 2012;287(42):35439-41.

30. Sargent JR, Bell JG, Bell MV, Henderson RJ, Tocher DR. Requirement criteria for essential fatty acids. J Appl Ichthyol. 1995;11:183-98.

31. Hochachka PW, Somero GN. Thermal optima and thermal tolerance limits. In: Biochemical adaptation- mechanisms and process in physiological evolution. Oxford: Oxford University Press; 2002. p. 428-38.

32. Hazel JR. Thermal adaptation in biological membranes: is homeoviscous adaptation the explanation? Annu Rev Physiol. 1995;57(1):19-42.

33. Masclaux H, Bec A, Kainz MJ, Desvilettes C, Jouve L, Bourdier G. Combined effects of food quality and temperature on somatic growth and reproduction of two freshwater cladocerans. Limnol Oceanogr. 2009;54(4):1323-32.

34. Pajk F, von Elert E, Fink P. Interaction of changes in food quality and temperature reveals maternal effects on fitness parameters of a keystone aquatic herbivore. Limnol Oceanogr. 2012;57(1):281-92.

35. Brzeziński T, von Elert E. Predator evasion in zooplankton is suppressed by polyunsaturated fatty acid limitation. Oecologia. 2015;179(3):687-97.

36. Martin-Creuzburg D, Sperfeld E, Wacker A. Colimitation of a freshwater herbivore by sterols and polyunsaturated fatty acids. P Roy Soc B-Biol Sci. 2009;276(1663):1805-14.

37. Montero D, Mathlouthi F, Tort L, Afonso JM, Torrecillas S, FernándezVaquero A, Negrin D, Izquierdo MS. Replacement of dietary fish oil by vegetable oils affects humoral immunity and expression of proinflammatory cytokines genes in gilthead sea bream Sparus aurata. Fish Shellfish Immunol. 2010;29(6):1073-81.

38. Benítez-Dorta V, Caballero MJ, Izquierdo M, Manchado M, Infante $C$, Zamorano MJ, Montero D. Total substitution of fish oil by vegetable oils in Senegalese sole (Solea senegalensis) diets: effects on fish performance, biochemical composition, and expression of some glucocorticoid receptorrelated genes. Fish Physiol Biochem. 2013;39(2):335-49.

39. Hixson SM, Arts MT. Climate warming is predicted to reduce omega-3, longchain, polyunsaturated fatty acid production in phytoplankton. Glob Chang Biol. 2016;22(8):2744-55.

40. Heckmann L-H, Sibly RM, Timmermans MJ, Callaghan A. Outlining eicosanoid biosynthesis in the crustacean Daphnia. Front Zool. 2008;5(1):1-9.

41. Heckmann L-H, Sibly RM, Connon R, Hooper HL, Hutchinson TH, Maund SJ, Hill CJ, Bouetard A, Callaghan A. Systems biology meets stress ecology: linking molecular and organismal stress responses in Daphnia magna. Genome Biol. 2008;9(2):R40.

42. Schlotz N, Sørensen JG, Martin-Creuzburg D. The potential of dietary polyunsaturated fatty acids to modulate eicosanoid synthesis and reproduction in Daphnia magna: a gene expression approach. Comp Biochem Physiol A Mol Integr Physiol. 2012;162(4):449-54.

43. Fink P, Windisch HS. The essential omega-3 fatty acid EPA affects expression of genes involved in the metabolism of omega-6-derived eicosanoids in Daphnia magna. Hydrobiologia. 2018. ISSN 0018-8158.

44. Monroig Ó, Tocher DR, Navarro JC. Biosynthesis of polyunsaturated fatty acids in marine invertebrates: recent advances in molecular mechanisms. Marine Drugs. 2013;11(10):3998-4018.

45. Lampert W, Trubetskova I. Juvenile growth rate as a measure of fitness in Daphnia. Funct Ecol. 1996;10(5):631-5.

46. Andrews S: FastQC: a quality control tool for high throughput sequence data. 2010 Available online at: http://www.bioinformaticsbabrahamacuk/ projects/fastqc.

47. Hulsen T, de Vlieg J, Alkema W. BioVenn - a web application for the comparison and visualization of biological lists using area-proportional Venn diagrams. BMC Genomics. 2008;9(1):488.

48. Brett MT, Müller-Navarra DC, Ballantyne AP, Ravet JL, Goldman CR. Daphnia fatty acid composition reflects that of their diet. Limnol Oceanogr. 2006;51(5):2428-37.

49. Sommer U. Plankton ecology: succession in plankton communities. Berlin: Springer-Verlag; 1989.

50. Sperfeld E, Wacker A. Temperature affects the limitation of Daphnia magna by eicosapentaenoic acid, and the fatty acid composition of body tissue and eggs. Freshw Biol. 2012;57(3):497-508.

51. von Elert E, Fink P. Global Warming: Testing for Direct and Indirect Effects of Temperature at the Interface of Primary Producers and Herbivores Is Required. Front Ecol Evol. 2018;6:87.

52. Schlotz N, Roulin A, Ebert D, Martin-Creuzburg D. Combined effects of dietary polyunsaturated fatty acids and parasite exposure on eicosanoidrelated gene expression in an invertebrate model. Comp Biochem Physiol A Mol Integr Physiol. 2016;201:115-23.

53. Stanley DW. Eicosanoids in invertebrate signal transduction systems. Princeton: Princeton University Press; 2000.

54. Gracey AY, Fraser EJ, Li W, Fang Y, Taylor RR, Rogers J, Brass A, Cossins AR. Coping with cold: an integrative, multitissue analysis of the transcriptome of a poikilothermic vertebrate. P Natl Acad Sci USA. 2004;101(48):16970-5.

55. Windisch HS, Frickenhaus S, John U, Knust R, Portner HO, Lucassen M. Stress response or beneficial temperature acclimation: transcriptomic signatures in Antarctic fish (Pachycara brachycephalum). Mol Ecol. 2014;23(14):3469-82.

56. Causton HC, Ren B, Koh SS, Harbison CT, Kanin E, Jennings EG, Lee TI, True $\mathrm{HL}$, Lander ES, Young RA. Remodeling of yeast genome expression in response to environmental changes. Mol Biol Cell. 2001;12(2):323-37.

57. Yampolsky LY, Zeng E, Lopez J, Williams PJ, Dick KB, Colbourne JK, Pfrender ME. Functional genomics of acclimation and adaptation in response to thermal stress in Daphnia. BMC Genomics. 2014;15(1):859.

58. Yee DC, Shlykov MA, Västermark Å, Reddy VS, Arora S, Sun El, Saier MH. The transporter-opsin-G protein-coupled receptor (TOG) superfamily. FEBS J. 2013;280(22):5780-800.

59. Cooper G. Signaling in Development and Differentiation. In: Sunderland M, editor. The Cell: A Molecular Approach. 2nd ed. Sunderland: Sinauer Associates; 2000.

60. Serhan CN, Chiang N, Dalli J, Levy BD. Lipid Mediators in the Resolution of Inflammation. Cold Spring Harb Perspect Biol. 2014;7(2):a016311.

61. Weiss Linda C, Leese F, Laforsch C, Tollrian R. Dopamine is a key regulator in the signalling pathway underlying predator-induced defences in Daphnia. Proc R Soc B Biol Sci. 2015;282(1816):20151440.

62. Arnold C, Konkel A, Fischer R, Schunck W. Cytochrome P450-dependent metabolism of omega- 6 and omega-3 long-chain polyunsaturated fatty acids. Pharmacol Rep. 2010;62(3):536-47.

63. Wada M, DeLong CJ, Hong YH, Rieke CJ, Song I, Sidhu RS, Yuan C, Warnock $\mathrm{M}$, Schmaier AH, Yokoyama C, et al. Enzymes and receptors of prostaglandin pathways with Arachidonic acid-derived versus Eicosapentaenoic acid-derived substrates and products. J Biol Chem. 2007; 282(31):22254-66.

64. Nelson DR, Goldstone JV, Stegeman JJ. The cytochrome P450 genesis locus: the origin and evolution of animal cytochrome P450s. Philos Trans R Soc B Biol Sci. 2013;368(1612):20120474

65. Baldwin WS, Marko PB, Nelson DR. The cytochrome P450 (CYP) gene superfamily in Daphnia pulex. BMC Genomics. 2009;10(1):169.

66. Jeyasingh PD, Ragavendran A, Paland S, Lopez JA, Sterner RW, Colbourne JK. How do consumers deal with stoichiometric constraints? Lessons from functional genomics using Daphnia pulex. Mol Ecol. 2011;20(11):2341-52. 
67. Schwarzenberger A, Fink P. Gene expression and activity of digestive enzymes of Daphnia pulex in response to food quality differences. Comp Biochem Physiol B: Biochem Mol Biol. 2018;218:23-9.

68. Sawicka KM, Seeliger M, Musaev T, Macri LK, Clark RAF. Fibronectin interaction and enhancement of growth factors: importance for wound healing. Adv Wound Care. 2015;4(8):469-78.

69. Neves SR, Ram PT, lyengar R. G protein pathways. Science. 2002;296(5573): 1636-9.

70. Sperfeld E, Wacker A. Maternal diet of Daphnia magna affects offspring growth responses to supplementation with particular polyunsaturated fatty acids. Hydrobiologia. 2015;755(1):267-82.

71. von Elert $E$, Wolffrom T. Supplementation of cyanobacterial food with polyunsaturated fatty acids does not improve growth of Daphnia. Limnol Oceanogr. 2001;46(6):1552-8.

72. Zehnder A, Gorham PR. Factors influencing the growth of Microcystis Aeruginosa Kütz. Emend Elenkin. Can J Microbiol. 1960;6(6):645-60.

73. von Elert E, Jüttner F. Phosphorus limitation not light controls the exudation of allelopathic compounds by Trichormus doliolum. Limnol Oceanogr. 1997; 42(8):1796-802.

74. Martin-Creuzburg D, von Elert E, Hoffmann KH. Nutritional constraints at the cyanobacteria-Daphnia magna interface: the role of sterols. Limnol Oceanogr. 2008;53(2):456-68.

75. Becker C, Boersma M. Resource quality effects on life histories of Daphnia. Limnol Oceanogr. 2003;48(2):700-6.

76. Fink P. Invasion of quality: high amounts of essential fatty acids in the invasive Ponto-Caspian mysid Limnomysis benedeni. J Plankton Res. 2013; 35(4):907-13.

77. Sperfeld E, Wacker A. Effects of temperature and dietary sterol availability on growth and cholesterol allocation of the aquatic keystone species Daphnia. J Exp Biol. 2009;212(19):3051-9.

78. Bolger AM, Lohse M, Usadel B. Trimmomatic: a flexible trimmer for Illumina sequence data. Bioinformatics. 2014;30(15):2114-20.

79. Li B, Dewey CN. RSEM: accurate transcript quantification from RNA-Seq data with or without a reference genome. BMC Bioinformatics. 2011;12:323.

80. Langdon WB. Performance of genetic programming optimised Bowtie2 on genome comparison and analytic testing (GCAT) benchmarks. BioData Min. 2015;8(1):1.

81. Powell S, Forslund K, Szklarczyk D, Trachana K, Roth A, Huerta-Cepas J, Gabaldón T, Rattei T, Creevey C, Kuhn M, et al. eggNOG v4.0: nested orthology inference across 3686 organisms. Nucleic Acids Res. 2014; 2(Database issue):D231-9.

82. Howe EA, Sinha R, Schlauch D, Quackenbush J. RNA-Seq analysis in MeV Bioinformatics. 2011;27(22):3209-10.

83. Robinson MD, McCarthy DJ, Smyth GK. edgeR: a bioconductor package for differential expression analysis of digital gene expression data. Bioinformatics. 2010;26(1):139-40.

84. Schwarzenberger A, Courts C, von Elert E. Target gene approaches: gene expression in Daphnia magna exposed to predator-borne kairomones or to microcystin-producing and microcystin-free Microcystis aeruginosa. BMC Genomics. 2009:10:527.

85. Schwarzenberger A, Kuster CJ, Elert E. Molecular mechanisms of tolerance to cyanobacterial protease inhibitors revealed by clonal differences in Daphnia magna. Mol Ecol. 2012;21(19):4898-911.

\section{Publisher's Note}

Springer Nature remains neutral with regard to jurisdictional claims in published maps and institutional affiliations.

Ready to submit your research? Choose BMC and benefit from:

- fast, convenient online submission

- thorough peer review by experienced researchers in your field

- rapid publication on acceptance

- support for research data, including large and complex data types

- gold Open Access which fosters wider collaboration and increased citations

- maximum visibility for your research: over $100 \mathrm{M}$ website views per year

At BMC, research is always in progress.

Learn more biomedcentral.com/submissions 